\title{
Developing responsive marketing system concept: Applying system dynamics approach
}

\author{
Nastaran Hajiheydari, Seyed Behnam Khakbaz", Ali Amoei Ojaki \\ Faculty of Management, University of Tehran, Tehran, Iran \\ Email address: \\ nhheidari@ut.ac.ir (N. Hajiheydari), Khakbazbehnam@yahoo.com (S. B. Khakbaz), ali_amoei@ut.ac.ir (A. A. Ojaki)
}

To cite this article:

Nastaran Hajiheydari, Seyed Behnam Khakbaz, Ali Amoei Ojaki. Developing Responsive Marketing System Concept: Applying System Dynamics Approach. Science Journal of Business and Management. Vol. 2, No. 3, 2014, pp. 91-96. doi: 10.11648/j.sjbm.20140203.11

\begin{abstract}
Marketing policies and strategies have long term effects on firm's financial indicators. Measuring these longterm effects is somehow difficult and it could be important from managers' viewpoint as well. Up to now a lot of researches have been done to disclose these effects, but the previous studies have limitation in demonstration of these long-term effects. In this article, we applied system dynamics for developing a dynamic marketing system and analyzing different marketing policies and strategies on firm's financial measurements. For this purpose, we proposed a dynamic marketing system model. The conceptual framework for dynamic model has been extracted by analyzing literature. In this regard, we studied related papers and determined the boundaries of marketing system by realizing important variables. Furthermore literatures have been analyzed for identifying relationships between marketing factors in a dynamic marketing system. As a result, most important positive reinforcement and negative balancing loops in this marketing system have been described in a comprehensive manner. In fact, the proposed marketing system can be applied in different industries and firms by customization for the firm's conditions and developing a quantitative dynamic marketing system.
\end{abstract}

Keywords: Marketing System, System Dynamics, Qualitative Dynamic Marketing System, Marketing Effectiveness

\section{Introduction}

In today market, where competition is highly intense, innovation is abundant; technologies are complex and market growth very rapid. As the market changes, marketing systems emerge, grow, adapt and evolve. So the marketing managers need to understand the dynamics which influence the structure of the industry in order to assess their decision about market [1]. However system dynamics rarely had been used in marketing. In this article we would develop a dynamic marketing system which can be used in policy making and strategy planning in marketing. The main article's question that we aimed to answer is:

Can marketing factors develop a marketing system which can be applied as a dynamic marketing system for analyzing different marketing policies and strategies?

Up to now, system dynamics applied for different analysis in marketing. These analyses consist of prediction market, demand, competitor behavior and also strategic policy making. Sheth and Sisodia in 2002 conducted one of the first researches about applying system dynamics in marketing. They proposed system dynamics and system thinking for calculating customer equity that they believe is marketing productivity issue. They apply system dynamics in four different systems: (a) market system, (b) acquisition and churn system (c) revenue per customer and total revenue system (d) customer NPV system [2]. In this papers proposed system dynamics model, all these systems (subsystems) have been used in an integrated fashion with each other and other subsystems and variables. System (a) is a portion of market part of our system, system (b) is a portion of customer part of our system and also system (c) and system (d) are a portion of financial part of our system.

Developing a dynamic model for analyzing customer relationship management (CRM) in different industries is one of the system dynamics applications in marketing. Chan et al. in 2010 developing a three tiers or module dynamic model for CRM. Their dynamic model consists of a customer purchasing behavior model (module 1), Markov chain model (module 2) and a financial returns model (module 3). In these models, by considering marketing activities and product attractiveness to the customer, the probability that a customer will repurchase/purchase modeled in module 1 . Then this probability used in module 2 for calculating customer lifetime value (CLV), and at last 
CLV applied in third module to predict return on investment in long term [3]. This paper proposed model also uses a market part which showing market situations, a customer part which shown the condition of a firm's customer (their adaptation rate and churn rate) and a financial part which shows the strategic decision results in long term. Moreover our model has another part which input marketing mix policies of the firm. It must be noted the purpose of our proposed quantitative dynamic model in this paper is to analyze the marketing mix policies and reveal long-term financial results. And also we consider a brand part in our qualitative dynamic model in this paper.

Our most important contribution in this article is developing a comprehensive dynamic marketing system, which considers most important marketing factors.

After discussion about system dynamics application in marketing, we would study marketing literature to identify the boundary of proposed system. Then this paper's approach and methodology (System Dynamics) would survey in literature. Findings, is the next section which allocate to proposed a dynamic marketing system, its boundary and also loops and its specification.

\section{Literature}

Eusebio et al. recognized six different factors, which are important in measuring marketing effectiveness. These six factors are financial, competitive market, consumer behavior, direct customer and innovation [4]. Other research identified financial, competitive, consumer behavior, direct trade customer and innovativeness [5], customer philosophy, operational efficiency, strategic orientation, marketing information and integrated marketing organization [6], or Marketing culture, marketing capability, marketing process, marketing performance and financial performance [7]. In this paper's proposed models (quantitative and qualitative), we used these group factors except innovation.

Eusebio et al. in 2006 shows consumer metrics, that is, regularly measuring the customer satisfaction level, consumer loyalty, new customer gained, customer retained or customer lost, are leading indicator of financial metrics [4]. In 2009, Gladson Nwokah proposed customer satisfaction, customer loyalty, new customer gained, and customer retained or customer lost (consumer metrics) are most vital factors which managers should give them priority. Also they proposed competitors are very important factor in market factors performance [8]. Frösén et Al. in 2012, Identifying sales, profit, gross margin, perceived quality, total number of consumers, consumers satisfaction, market share, awareness, marketing spending and consumer complaints as the most important factors in measuring marketing performance [9]. Factors like relative price, commitment [10], relative perceived quality [11], share of advertisement, promotional share, penetration, number of newly acquired customers [12] and [13], tangible resources [14], market growth, company market position, potential sales volume, number of current competitor, development process cost, brand image [15], market size, market segment, relative value, advertisement spend [16], purchase intent [17], actual/potential customer/segment [18] also recognized by different researchers. In our model we used this concept and show a cause and effect relationship between these factors.

Gama in 2011, Identified a casual relationship between different factors in marketing. This relationship begins with factors like quality which categorized in marketing culture and marketing strategy like factors in marketing capability category. This relationship continued with marketing process and then factors like customer loyalty, brand equity and market share in market performance category. This model ended with financial performance indicator [7]. Also Grønholdt and Martensen in 2006, proposed a relationship which begin with marketing action (marketing policy in our model), then proceed by mental consumer results (customer satisfaction), behavioral customer results (customer churn, new customer and enterprise sell), Market results (branding variables) and end with financial results [19]. Theodosiou et al. identified different relationships between marketing factors. Their model begins with market turbulence; intensity of competition and decentralization, then proceeded by customer orientation, competitor orientation, internal/cost orientation, innovation orientation and then ended with marketing capability. This model in some aspects is very similar to our introduced dynamic model in this article [20]. Ambler in 2000, proposed a typical business map which considered marketing in it [21]. This business map can be seen in figure 1 . These relationships also applied in our models in this paper.

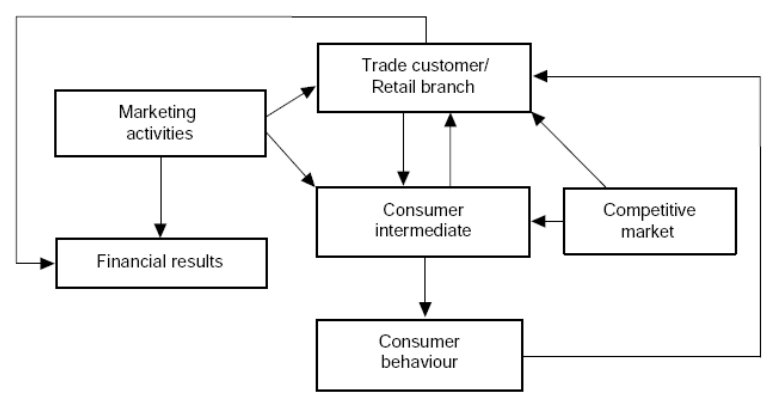

Figure 1. Tim Ambler proposed typical business map [21].

\section{Methodology (System Dynamics)}

System dynamics is an approach to understanding the behavior of complex systems over time. It deals with internal feedback loops and time delays that affect the behavior of the entire system [22]. System dynamics is a methodology for studying and managing complex feedback systems, which one finds in business and other social systems. In fact, it has been used to address practically every sort of feedback system [23]. What makes using system dynamics different from other approaches to studying complex systems is the use of feedback loops and stocks and flows. These elements help describe how even 
seemingly simple systems display baffling nonlinearity. Also System dynamics is a computer-aided approach to policy analysis and design. It applies to dynamic problems arising in complex social, managerial, economic, or ecological systems literally any dynamic systems characterized by interdependence, mutual interaction, information feedback, and circular causality.

System dynamics originally developed in the 1950s from the work of Jay W. Forrester. To help corporate managers improve their understanding of industrial processes. His seminal book Industrial Dynamics [22] is still a significant statement of philosophy and methodology in the field. Within ten years of its publication, the span of applications grew from corporate and industrial problems to include the management of research and development, urban stagnation and decay, commodity cycles, and the dynamics of growth in a finite world. It is now applied in economics, public policy, environmental studies, defense, and theorybuilding in social science, and other areas, as well as its home field, management. The name industrial dynamics no longer does justice to the breadth of the field, so it has become generalized to system dynamics. The modern name suggests links to other systems methodologies, but the links are weak and misleading. System dynamics emerges out of servomechanisms engineering, not general systems theory or cybernetics [24].

System dynamics is currently being used throughout the public and private sector for policy analysis and design [25].

The system dynamics approach involves:

- Defining problems dynamically, in terms of graphs over time.

- Striving for an endogenous, behavioral view of the significant dynamics of a system, a focus inward on the characteristics of a system that themselves generate or exacerbate the perceived problem.

- Thinking of all concepts in the real system as continuous quantities interconnected in loops of information feedback and circular causality.

- Identifying independent stocks or accumulations (levels) in the system and their inflows and outflows (rates).

- Formulating a behavioral model capable of reproducing, by itself, the dynamic problem of concern. The model is usually a computer simulation model expressed in nonlinear equations, but is occasionally left un-quantified as a diagram capturing the stock-and-flow/causal feedback structure of the system.

- Deriving understandings and applicable policy insights from the resulting model.

- Implementing changes resulting from model-based understandings and insights.

Building a systemic model is not a simple task. It implies an iterative procedure in which the model could be rebuilt for several times. There is no best formula for developing a thriving systemic model. Furthermore, there is no best procedure that could assurance a useful systemic model, although a few main steps should be included in any modeling procedure, as stated in the following [36]:

1. Articulating the problem which needs to be addressed: Developing a systemic model needs clear defined boundary. Furthermore, a systemic model's boundary defined by problem's goal. Therefore, the most important part of a successful study is its goal and in the first step of a systemic study, the goal of the problem must be defined. In this article, introduction section has allotted to this step.

2. Formulating a dynamic hypothesis or a theory about the causes of the problem: In the second step for developing a systemic model, mental model of the problem must be described. This step is the aim of this article. In this step all of the variable must be identified and then their relationship must be described. A good systemic model must have endogenous variables, so as to can describe the behaviour of system. In this article, variables have identified and explained in literature section and then in findings section a mental model for marketing system would demonstrate.

3. Building a simulation model so as to test the dynamic hypothesis (beyond the scope of this paper).

4. Testing the model (beyond the scope of this paper).

5. Designing and evaluating policies (beyond the scope of this paper).

\section{Findings}

Because a complete system for marketing has a lot of variables, we consider a simpler system with most important factors which identified in marketing literature. These variables are below this paragraph (boundaries of system). We briefly descript indentified variables. Also the cause of these factors, that change them, and the effect factors of them which was identified from studied relationship from literature or by self knowledge of authors, would explain. Marketing Mix: this group is the most important group, which we want to know its effects on others marketing factors (cause of other factors that studied in this article's system).

Price: Price is one of the marketing mix elements, which has considerable effects on customers' intent to buying a product (Cause factors: Profit and Price Policy (input) and Effect factor: Customer Satisfaction).

Profit: Profit is a short term measurement for firm's success which is: Sell- Cost (Cause factors: Cost and Sell and Effect factors: Price and Promotional Cost).

Cost: Cost is the total cost of production and selling a product in a time period (Cause factors: Production Cost

Marketing Cost and Effect factor: Profit).

Sell: Sell is the total revenue of selling a product in a time period (Cause factors: Total Customer and Customer Satisfaction and Effect factor: Customer Satisfaction).

Quality: Quality is the quality of product, relative to base product (product in the beginning of simulation) and is a 
Product" important factor (Cause factors: Profit and Quality Policy (input) and Effect factors: Cost and Customer Satisfaction).

Customer Satisfaction: Customer satisfaction is a measure of how products and services supplied by a company meet or surpass customer expectation (Cause factors: Price and Quality and Effect factors: Customer Loyalty, Customer Complaint and sell).

Customer Loyalty: Customer loyalty is all about attracting the right customer, getting them to buy, buy often, buy in higher quantities and bring you even more customers (Cause factor: Customer Satisfaction and Effect factor: Customer Churn).

Customer Complaint: Number of complaints which customers declared (Cause factor: Customer Satisfaction and Effect factor: Customer Churn).

Customer Churn: Number of customer that firm loss because of their unexpected service or product (Cause factors: Customer Loyalty and Customer Complaint and Effect factors: Total Customer).

New Customer: Potential customer in the market which adapt by firm (Cause factor: Brand Equity and Effect factor: Total Customer.

Total Customer: Total number of customers: Total Customer + New Customer - Customer Churn (Cause Factors: New Customer and Customer Churn and Effect factor: Market Share.

Market Share: Market share is the percentage of a market (defined in terms of either units or revenue) accounted for by a specific entity. In this paper is: Total Customers divided by Market Size (Cause factors: Total Customer and Market Size and Effect factors: Brand Awareness, Promotion Cost, and Advertisement Cost).

Brand Equity: Brand equity is a phrase used in the marketing industry which describes the value of having a well-known brand name, based on the idea that the owner of a well-known brand name can generate more money from products with that brand name than from products with a less well known name, as consumers believe that a product with a well-known name is better than products with less well known names (Cause factors: Brand Awareness and Brand Image and Effect factor: New Customer).

Brand Awareness: Brand Awareness is the extent to which a brand is recognized by potential customers, and is correctly associated with a particular product (Cause factors: Advertisement Cost and Market Share and Effect factor: Brand Equity).

Brand Image: The impression in the consumers' minds of a brand's total personality (real and imaginary qualities and shortcomings), (Cause factors: Quality and Effect factor: Brand Equity).

Promotion Cost: Promotion Cost is the total cost which a firm conducted for personal marketing (this paper's description), (Cause factors: Market Share, Profit and Promotion Policy (input) and Effect factor: Market Share).

Advertisement Cost: Advertisement Cost is the total cost which a firm conducted for Public marketing (this paper's description), (Advertisement Policy (input) and Effect factor: Market Growth).

Market Size: Market Size is the total number of potential customer in the society (Cause factor: Market Growth and Effect factor: Market Share).

Market Growth: Market Growth is the ratio of Market which added to Market Size in each time period. This factor is the effects of public advertisement and word of mouth about a product (Cause factor: Advertisement Cost and Competitor Advertisement Cost and Effect factor: Market Size).

Number of Competitor: Total number of a firm competitor in a market (Cause factor: Market Size and Effect factor: Competitor Advertisement Cost).

Competitor Advertisement Cost: Total cost of competitor's advertisement in the market (Cause factor: Number of Competitor and Effect factor: Market Growth).

Up to now we described comprehensive variables of this paper's qualitative dynamic model. Now it's time for illustrating models and its loops. Qualitative dynamic model of this article is shown in figure 2 and its loops descriptions are below of this paragraph (variable relationships are in the parenthesis). Also it must notice that only most important loops are described, and the others are not in the scope of this article.

R\&D, a negative balancing loop (Quality-CostContribution Margin- Profit- Quality): This loop shows that if a firm has a Quality Policy for increasing quality of its product, then the quality of its product increased. But this increase, effects on the increasing production cost which causes decreasing profit and results in diminishing product quality.

Customer, a positive reinforcing loop (QualityPerceived Quality- Relative Perceived Quality- Customer Satisfaction- Customer Complaint (Customer LoyaltyCustomer Commitment)- Customer Churn- Total Customer- Sell Contribution Margin- Profit- Quality): This loop shows that if a firm has a Quality Policy for increasing quality of its product, then the quality of its product increased. This increasing by a delay causes increasing in Perceived Quality. Increasing perceived quality of a product in comparison with others product in market gained more customer satisfaction for the producer. Satisfied customers are more loyal and have fewer complaints which this results in fewer customers who goes to competitors and churned. If customer churn decreased, total customers increased and also total sell of firms increased which results in higher Contribution Margin and also Profit. Increasing profit and as a result, investing on improving quality, caused improvement of product quality. It must be noticed that the results of this loop is independent on $R \& D$ loop, because total performance of this two loops can be positive or negative, according to Quality Policy, therefore Quality Policy is must carefully determined.

Pricing, a positive reinforcing loop (Price- Relative Price- Customer Satisfaction- Sell- Contribution MarginProfit- Price): If a firm decided to raise its product's price, 
its customer satisfactory decreased which caused its sell decreased. By decreasing revenue of a firm, its contribution margin and also its profit decreased. This can be leads the firm to rises the prices and this loop iterate and firm losses more customer satisfaction.

Advertisement, a positive reinforcing loop (Ad CostTotal Ad Cost- Market Growth- Market Size- Market Share- Ad Cost): Firm's policy for rising advertisement cost causes market growth which shrinkage Market Share of the firms. Also this reduction in market share effects on advertisement cost and raises it up more. It must be noticed that advertisement cost increased brand awareness and brand identity of the firm, so it must carefully determined.

Promotion, a negative balancing loop (Promotion CostRelative Promotion Cost- Market Penetration- Market Share- Promotion Cost): Increasing promotion cost raises the Relative Promotion Cost of the firm, compared with its competitor. It can be lead to more penetration in market segment and improving Market Share of the firm. Increasing market share satisfied managers and leads them to decreasing promotion cost (for improving profit), so the loop balanced itself.

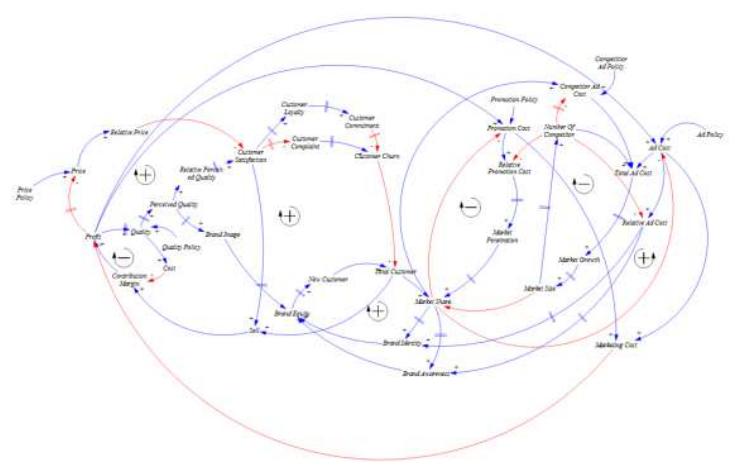

Figure 2. Qualitative dynamic marketing system.

\section{Conclusion}

One of the most important issues in marketing is long term effects of marketing policies and strategies. In this article we developed a dynamic marketing system thatcould be used for assessing marketing policies and strategies' long-term effects on firm's success. For developing a system dynamics model, variable thataffects on the system must be identified. In this article we identified marketing system variables and their relationships from marketing and system dynamics literature. By identifying these variables, dynamic marketing system boundaries recognized. Then a qualitative dynamic marketing system model developed and most important positive reinforcement and negative balancing loops in this marketing system, described. This dynamic marketing system is more comprehensive than marketing system in literature [3] and [2]. Their marketing systems considered only a section of complete marketing system, which this article's dynamic marketing system, had been introduced a more complete marketing system. This comprehensive marketing system can be applied in different industries and firms. This can be done by customization for the firm's conditions and developing a quantitative dynamic marketing system for its situation. In brief this article has been demonstrating a comprehensive dynamic marketing system.

\section{References}

[1] M. Pagani and P. Otto, "Integrating strategic thinking and simulation in marketing strategy: Seeing the whole system Journal of Business Research," Journal of Business Research, pp. 1568-1575, 2013.

[2] J. N. Sheth and R. S. Sisodia, "Marketing productivity Issues and analysis," Journal of Business Research, p. 349$362,2002$.

[3] S. Chan, W. Ip and V. Cho, "A model for predicting customer value from perspectives of product attractiveness and marketing strategy," Expert Systems with Applications, pp. 1207-1215, 2010.

[4] R. Eusebio, J. L. Andreu and M. P. L. Belbeze, "Measures of marketing performance: a comparative study from Spain," International Journal of Contemporary Hospitality Management, pp. 145-155, 2006.

[5] T. Ambler, F. Kokkinaki, S. Puntoni and D. Riley, "Assessing Market Performance: The Current State of Metrics," Centre for Marketing Working Paper, 2001.

[6] K. Appiah-Adu, A. Fyall and S. Singh, "Marketing effectiveness and business performance in the financial services industry," Journal of Services Marketing, pp. 18-34, 2001.

[7] A. P. d. Gama, "An expanded model of marketing performance," Marketing Intelligence \& Planning, pp. 643661, 2011.

[8] N. G. Nwokah, "Customer-focus, competitor-focus and marketing performance," Measuring Business Excellence, pp. 20-28, 2009.

[9] J. Frösén, H. Tikkanen, M. Jaakkola and A. Vassinen, "Marketing Performance Assessment Systems and the Business Context," European Journal of Marketing, 2012.

[10] T. Ambler and W. Xiucun, "Measures of Marketing Success: A Comparison Between China and the United Kingdom," Asia Pacific Journal of Management, pp. 267-281, 2003.

[11] T. Ambler, F. Kokkinaki and S. Puntoni, "Assessing Marketing Performance: Reasons for Metrics Selection," Journal of Marketing Management, pp. 475-498, 2004.

[12] J. Llonch, R. Eusebio and T. Ambler, "Measures of Marketing Success: A Comparison Between Spain and the UK," European Management Journal, pp. 421-422, 2002.

[13] M. Solcansky, L. Sychrova and F. Milichovsky, "MARKETING EFFECTIVENESS BY WAY OF METRICS," ECONOMICS AND MANAGEMENT, pp. 1323-1328, 2011.

[14] R. E. Morgan and S. D. Hunt, "Determining Marketing Strategy A cybernetic systems approach to scenario planning," European Journal of Marketing, pp. 450-478, 2002. 
[15] A. I. Jiménez-Zarco, M. P. Martínez-Ruiz and Ó. GonzálezBenito, "PERFORMANCE MEASUREMENT SYSTEM (PMS) INTEGRATION INTO NEW PRODUCT INNOVATION: A LITERATURE REVIEW AND CONCEPTUAL FRAMEWORK," Academy of Marketing Science Review, pp. 1-15, 2006.

[16] H. J. Davidson, "Transforming the Value of Company Reports through Marketing Measurement," Journal of Marketing Management, pp. 757-777, 1999.

[17] C. H. Sampaio, C. Simões, M. G. Perin and A. Almeida, "Marketing metrics: Insights from Brazilian managers," Industrial Marketing Management, pp. 8-16, 2011.

[18] P. Barwise and J. U. Farley, "Marketing Metrics: Status of Six Metrics in Five Countries," European Management Journal, p. 257-262, 2004.

[19] L. Grønholdt and A. Martensen, "Key Marketing Performance Measures," The Marketing Review, pp. 243252, 2006.

[20] M. Theodosiou, J. Kehagias and E. Katsikea, "Strategic orientations, marketing capabilities and firm performance: An empirical investigation in the context of frontline managers in service organizations," Industrial Marketing Management, pp. 1058-1070, 2012.

[21] T. Ambler, "Marketing Metrics," Business Strategy Review, pp. 59-66, 2000.

[22] J. Forrester, Industrial Dynamics, Waltham, MA.: MIT Press, Reprinted by Pegasus Communications, 1961.

[23] N. Hajiheydari and B. Zarei, "Developing and manipulating business models applying system dynamics approach," Journal of Modelling in Management, pp. 155-170, 2013.

[24] G. Richardson and A. Pugh, Introduction to System Dynamics Modeling with DYNAMO, Waltham, MA: Cambridge MA: The MIT Press. Reprinted by Pegasus Communications, 1981.

[25] J. W. Forrester, Urban dynamics, Pegasus Communications, 1969.

[26] R. A. Layton, "Towards a theory of marketing systems," European Journal of Marketing, pp. 259-276, 2011.

[27] A. G. Woodside, "Firm orientations, innovativeness, and business performance: Advancing a system dynamics view following a comment on Hult, Hurley, and Knight's 2004 study," Industrial Marketing Management, p. 275- 279, 2005.

[28] G. Fath and M. Sarvary, "Adoption Dynamics in Buyer-Side Exchanges," Quantitative Marketing and Economics, p. 305-335, 2003.
[29] R. M. Yawson and J. Kuzma, "Systems Mapping of Consumer Acceptance of Agrifood Nanotechnology," Journal of Consumer Policy, p. 299-322, 2010.

[30] A. G. Woodside and W. G. Biemans, "Modeling innovation, manufacturing, diffusion and adoption/rejection processes," Journal of Business \& Industrial Marketing, p. 380-393, 2005.

[31] Y.-H. Hsieh and S.-T. Yuan, "Modeling service experience design processes with customer expectation management A system dynamics perspective," Kybernetes, pp. 1128-1144, 2010.

[32] J. A. M. Garcia and L. M. Caro, "Understanding customer loyalty through system dynamics The case of a public sports service in Spain," Management Decision, pp. 151-172, 2009.

[33] P. Farris, W. Verbeke, P. Mdickson and E. Van Nierop, "Path Dependencies and the Long-term Effects of Routinized Marketing Decisions," Marketing Letters, p. 247-268, 1998.

[34] E. D. Adamides and M. Voutsina, "The double-helix model of manufacturing and marketing strategies," International Journal of Production Economics, pp. 3-18, 2006.

[35] J. D. Sterman, "System dynamics modeling: Tools for learning in a complex world," California Management Review, pp. 8-25, 2001.

[36] J. D. Sterman, Business Dynamics. Systems Thinking and Modeling for a Complex World, Boston, MA.: Irwin McGraw-Hill, 2000.

[37] J. W. Forrester, "Industrial dynamics: A major breakthrough for decision makers," Harvard Business Review, pp. 37-66, 1958.

[38] K. Stave, "Using system dynamics to improve public participation in environmental decisions," System Dynamics Review, p. 139-167, 2002.

[39] F. Barnabe, "A "system dynamics-based Balanced Scorecard" to support strategic decision making Insights from a case study," International Journal of Productivity and Performance Management, pp. 446-473, 2011.

[40] P. Senge, The Fifth Discipline: The Art and Practice of the Learning Organization, Doubleday/Currency, 1990.

[41] D. Aaker, "Measuring Brand Equity Across Products and Markets," CAUFORNIA MANAGEMENT REVIEW, pp. 102-120, 1996. 